\title{
HIV associated pulmonary emphysema: a review of the literature and inquiry into its mechanism
}

\author{
I Petrache, ${ }^{1}$ K Diab, ${ }^{1}$ K S Knox, ${ }^{1}$ H L Twigg III, ${ }^{1}$ R S Stephens, ${ }^{2}$ S Flores, ${ }^{3}$ R M Tuder ${ }^{4}$
}

${ }^{1}$ Division of Pulmonary, Allergy, Critical Care and Occupational Medicine, Department of Medicine, Indiana University, Indianapolis, Indiana, USA; ${ }^{2}$ Division of Pulmonary and Critical Care Medicine, Department of Medicine, University of Colorado, Colorado, USA; ${ }^{3}$ Department of Medicine, University of Colorado, Colorado, USA; ${ }^{4}$ Division of

Cardiopulmonary Pathology,

Department of Pathology, Johns Hopkins University School of

Medicine, Baltimore, Maryland, USA

Correspondence to:

Dr I Petrache, Indiana University, Division of Pulmonary, Allergy, Critical Care and Occupationa Medicine, Van Nuys Medical Science Building, 635 Barnhill Drive, MS224, Indianapolis, IN 46202-5120, USA; ipetrach@iupui.edu

Received 1 February 2007 Revised 17 April 2007 Accepted 9 May 2007

\section{ABSTRACT}

Chronic lung diseases are increasingly recognised complications of the human immunodeficiency virus (HIV) infection and acquired immune deficiency syndrome (AIDS). Of these, pulmonary emphysema, characterised by permanent destruction of the lung parenchyma distal to the terminal bronchioles accompanied by various degrees of inflammation, is emerging as a distinct source of morbidity for patients infected with HIV. Similarly, HIV is now frequently cited as a susceptibility factor for the development of emphysema, independent of cigarette smoking status. The presence of common coexistent confounding factors that may predispose patients to chronic lung injury such as drugs, opportunistic infections and malnutrition, limits the scope of studies of direct mechanisms involved in HIV associated emphysematous lung disease. We review the clinical studies supporting a direct association between HIV infection and emphysema. Recent developments in the basic understanding of HIV infection and emphysema are also reviewed, since they may aid in understanding the pathobiology of HIV associated emphysema. The authors emphasise how HIV infection may affect cytotoxic lymphocyte activation, lung capillary endothelial cell injury and apoptosis, sphingolipid imbalance and oxidative stress in the lung. A better understanding of the pathogenesis of HIV associated pulmonary emphysema may provide clues and therapeutic targets that have broader application in this disease, including cigarette smoke induced emphysema.

Before the advent of effective antiviral medications, opportunistic infections were early, inevitable and fatal consequences of acquired immune deficiency syndrome (AIDS). Pneumocystis jiroveci (former carinii) pneumonia (PCP) was the most common fatal complication, compromising about $75 \%$ of AIDS patients in the early years of the epidemic. Indeed, of the first 1000 cases of AIDS reported to the CDC, PCP was the AIDS defining illness in 580 patients. ${ }^{1}$ Tuberculosis, bacterial pneumonias and Kaposi's sarcoma, now known to be associated with human herpes virus 8 (HHV-8) infection, were also frequent occurrences in human immunodeficiency virus (HIV) infected patients. Together, these pulmonary complications were major sources of morbidity and mortality at the beginning of the epidemic.

HIV related bullous disease was first reported in the late 1980s. ${ }^{2}$ The description of bullous disease during radiological examination of the thorax in patients with AIDS provided the first hint that HIV infection was associated with emphysematous destruction of the distal lung parenchyma. ${ }^{3}$ Radiologically, emphysema manifests early as decreased attenuation of the lung parenchyma on CT images, usually in a centrilobular distribution, while more severe disease is characterised by larger usually round areas of hyperlucencies with thin walls, described as blebs or bullae (fig 1). Emphysema typically is a disease of cigarette smokers; however, only a minority of smokers develops the disease, over a prolonged period of time of two to three decades. Therefore, there is limited information about the cellular mechanisms behind the pathogenesis of cigarette smoke induced emphysema in the general population. In contrast, HIV associated emphysema occurs over a much shorter period of time than smoking related emphysema. For example, emphysema may be recognised in 20-40-year-old patients, rather than in the 50-70-year-old patients in non-HIV smokers. Insights into the pathogenesis of HIV related emphysema might help determine the pathogenesis of emphysema in the general population of smokers. HIV itself has been reported to cause direct cytotoxic effects in the brain and kidney cells, leading to conditions such as HIV dementia and HIV nephropathy, respectively. A similar effect could also occur in the lung, explaining the HIV associated emphysema in non-smokers. Alternatively, in smokers with HIV and emphysema, what is the underlying mechanism by which HIV infection augments the damage caused by tobacco smoke, to explain why the disease appears to occur earlier than in smokers without HIV? Is it unique to HIV infected patients, or could similar mechanisms apply to the pathogenesis of emphysema in the HIV negative population?

The purpose of this review is to discuss the clinical studies that established the link between HIV infection and emphysematous lung destruction in the light of experimental work that suggested a molecular mechanism for this destruction. This analysis could lead to improved understanding of the more general problem of emphysematous destruction of the lung.

\section{CLINICAL STUDIES OF HIV ASSOCIATED EMPHYSEMA}

The introduction of highly active antiretroviral therapy (HAART) in the mid 1990s, along with effective methods of PCP prophylaxis, greatly reduced the incidence of infectious pulmonary complications among HIV infected individuals. However, pulmonary complaints remained prominent among the HIV seropositive (HIV+) population, even in the absence of overt pulmonary complications. A survey of 327 patients revealed that HIV+ patients have a greater incidence of cough, phlegm production, dyspnoea and wheezing compared with HIV negative (HIV-) controls. ${ }^{4}$ This finding was independent of tobacco use. 

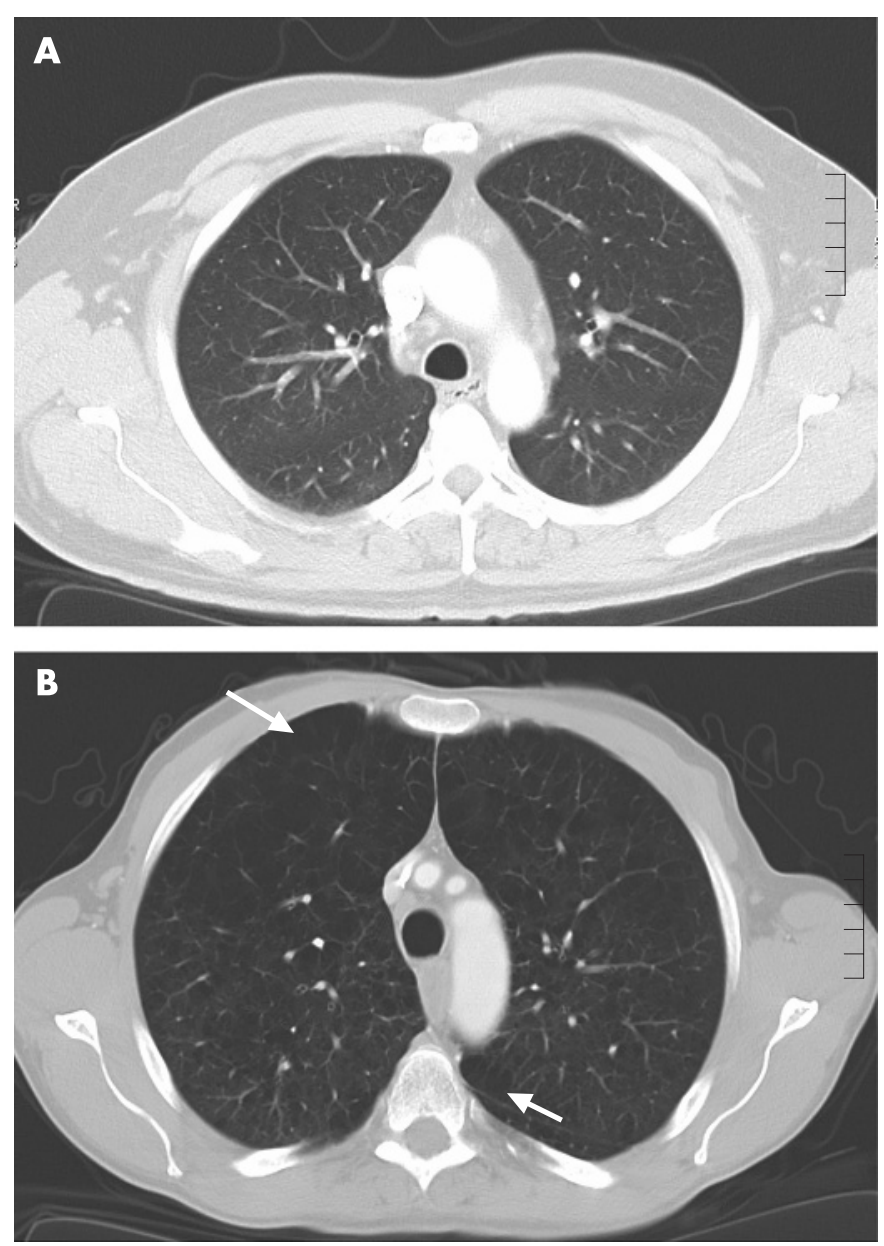

Figure 1 Radiological manifestations of HIV associated emphysema. (A) CT scan of the thorax (apical lung section at the level of the aortic arch) of a 56-year-old male, HIV positive since 2002, nadir CD4 $=72$ and not receiving antiretroviral therapy. Self-reported smoking history of 2 pack-years. Note the normal appearing lung structure. (B) CT scan of the thorax (apical lung section at the level of the aortic arch) of a 58-year-old male, HIV positive since 2001, nadir CD4 $=538$ and not receiving antiretroviral therapy. Self-reported smoking history of 21 pack-years. Despite a slight difference in the window level due to the different image acquisition technique, the differences from the CT scan in (A) are readily noted, such as the increased anteroposterior diameter of the chest and the widespread presence of low attenuation lung structures (arrow) consistent with extensive emphysema.

The symptoms of HIV related emphysema described by Diaz and colleagues ${ }^{4}$ are quite similar to the classic symptoms of pulmonary emphysema and chronic obstructive pulmonary disease. Early in the epidemic in 1989, Kuhlman et al published a case series of CT examinations in HIV+ patients. Twenty-three out of 55 patients had bullous changes identified on CT examination. ${ }^{2}$ Three years later, Diaz et al reported physiological evidence of emphysema-like disease in a small series of four HIV+ patients. In these patients, who ranged in age from 32 to 55 years and presented with dyspnoea but no history of pulmonary opportunistic infections or infiltrate on chest radiograph, pulmonary function tests revealed prominent air trapping and hyperinflation. Additionally, all had decreased carbon monoxide diffusion capacities. Although there was minimal evidence of obstruction, all three patients who underwent high resolution CT examinations had evidence of bullous changes. Because the changes in pulmonary function tests were disproportionate to the reported tobacco use, the authors postulated an increased susceptibility to cigarette smoke damage in HIV infected patients.

This hypothesis has been supported by further comparisons of HIV+ smokers with HIV smokers. In a recent observational study comparing 1014 HIV+ and 713 HIV - male veterans, HIV was identified as an independent risk factor for chronic obstructive pulmonary disease (COPD) after adjusting for age, race, pack-years of smoking, intravenous drug abuse and alcohol abuse. HIV subjects were $50-60 \%$ more likely to receive a diagnosis of COPD when these risk factors were accounted for. ${ }^{6}$ A series of 114 HIV+ patients, when compared with 44 HIVcontrols, revealed a significantly higher rate of emphysema (17/ 114 vs 1/44) among the HIV+ individuals. ${ }^{7}$ When controlled for tobacco exposure, the HIV+ subjects again had significantly more emphysematous damage for a given level of tobacco use. A significantly higher percentage of cytotoxic $\mathrm{T}$ lymphocytes were found in the bronchoalveolar lavage of HIV+ patients with emphysema than in any other group. ${ }^{7}$ As discussed further in the review, cytotoxic $\mathrm{T}$ lymphocytes are postulated to play a pathogenic role in the development of human emphysema. ${ }^{8}$ In the context of the HIV infection associated emphysema, cytotoxic $\mathrm{T}$ lymphocytes may be a marker of specific lung damage or may directly be involved in the pathogenesis of emphysematous lung destruction. Although the above discussed studies provide evidence of an association between HIV and emphysema, many features of this disorder are not clear Because emphysema develops earlier in HIV+ patients, the association between HIV infection and emphysema may reflect an increased susceptibility to tobacco damage. The increased susceptibility may be due to HIV decreasing the lung's ability to cope with the injury by cigarette smoking. However, neither the long term natural history of HIV associated emphysema is known nor is the effect of HIV treatment on its course. In the aforementioned VA study, which, importantly, was not designed to assess the effect of HAART on the development or progression of COPD, there was no significant difference in the number of patients diagnosed with COPD among those who received HAART therapy versus those who did not. ${ }^{6}$ In addition to the limitations in the study design, the lack of data on HAART adherence and effectiveness among the patients studied significantly impairs drawing any conclusions about the impact of HAART on COPD incidence or the clinical course in HIV infected individuals.

Adding to the complexity of HIV associated COPD, several risk factors associated with HIV infection may themselves play a pathogenic role in the development of emphysema, such as infection or colonisation with Pneumocystis, intravenous drug use, malnutrition, etc. Despite the decrease in the morbidity and mortality associated with PCP pneumonia, a large number of HIV+ patients, especially those with low CD4 cell counts, may be colonised with Pneumocystis. A recent study identified Pneumocystis in 42 of 91 (46\%) patients. ${ }^{9}$ The risk of colonisation increased with cigarette smoking but was not associated with CD4 count, use of prophylaxis, use of antiretroviral agents or prior PCP pneumonia. Other studies have found colonisation rates as high as $69 \% .{ }^{10}$ In the non-HIV infected population, Pneumocystis colonisation has been associated with increased severity of airway obstruction in COPD. ${ }^{11}$ In the studied cohort of patients, $36.7 \%$ of patients with Global Health Initiative on Obstructive Lung Disease (GOLD) stage IV disease were colonised with Pneumocystis compared with only 5.3\% of patients with less severe COPD or normal lung function. These data led to the hypothesis that Pneumocystis colonisation may accelerate the development of airway obstruction. Further 
studies of the pathogenic role of the fungal colonisation in the development of airspace enlargement in emphysema are needed to better understand the role of colonisation by Pneumocystis colonisation and infection in the pathogenesis of HIV related emphysema. A detailed understanding of these pathogenic mechanisms will likely require the use of a relevant animal model. Recently, investigators have reported on the development of such a model, of non-human primates infected with the simian immunodeficiency virus, then colonised with Pneumocystis who develop a progressive decline in lung function accompanied by influx of cytotoxic lymphocytes. ${ }^{12}$

The high risk of HIV infection in injecting drug users confounds the interpretation of emphysema in HIV+ individuals, since intravenous drug use has been associated with bullous lung disease. A large retrospective series found a $2 \%$ incidence of bullous pulmonary damage in intravenous drug users, with emphysematous changes typically present in the upper lobes. ${ }^{13} 14$ Interestingly, intravenous injection of crushed methylphenidate tablets (Ritalin) is associated with a panlobular emphysema mostly affecting the lower lobes of the lung. ${ }^{15} 16$ While this is different from the emphysema seen in other intravenous drug users and in chronic smokers, the radiographic and pathological presentations resemble the findings in patients with alpha 1-antitrypsin deficiency. Talc from the Ritalin tablets was implicated as a possible causative factor similar to that found in intravenous methadone preparations, ${ }^{17}$ possibly related to foreign body microemboli of the pulmonary capillary beds causing lower lobe emphysema which may coexist with interstitial fibrotic changes. ${ }^{18}$ Despite the fact that the use of marijuana is not a risk factor for HIV in patients who are habitual marijuana smokers, bullous lung disease has been described in association with the heavy use of marijuana. These marijuana associated bullae differ from tobacco associated emphysema in their distribution as they are typically located paraseptal, rather then centrilobular. ${ }^{19}$

\section{EXPERIMENTAL STUDIES AND MECHANISTIC THEORIES RELATED TO THE PATHOGENESIS OF EMPHYSEMA IN HIV+ INDIVIDUALS}

There is increasing appreciation that the pathogenesis of emphysema is a complex process that involves crosstalk between multiple physiological and pathological pathways of the lung. Immune, apoptotic, proteolytic and oxidative stress responses of multiple cell types converge to cause relentless lung destruction over a period of years. ${ }^{20}$ The elastase instillation model of emphysema developed by Senior et al provided the experimental validation of the causal role of excessive elastolytic burden in alveolar destruction in emphysema. ${ }^{21}$ In the present age of transgenic modelling of disease, the protection against cigarette smoke induced emphysema in mice deficient in matrix metalloprotease-12 solidified the protease/antiprotease hypothesis as a prime potential target for therapies against the disease. $^{22}$ Because the experimental evidence of excessive proteolysis developed in the past two decades, several human studies documented the activation of inflammatory cells in smokers and the presence of markers of inflammation in the blood, bronchoalveolar lavage and lung tissue. ${ }^{823} 24$ Several experimental studies documented that depletion of macrophages rendered rodents resistant to cigarette smoke induced emphysema. ${ }^{25}$

In parallel with studies on inflammatory cells, other investigators focused their research on the role of resident structural cells of the lung in emphysema. In the alveoli, $\mathrm{O}_{2}$ is transported from airspaces lined by epithelial cells to blood vessels lined by endothelial cells. Destruction of either of these cell types would result in the disappearance of alveolar units. In principle, cigarette smoke and other aetiological agents can cause emphysema ${ }^{26}$ by triggering apoptosis of either epithelial cells (direct mechanism) ${ }^{27}$ or endothelial cells (through downregulation of survival signalling molecules). ${ }^{26} 2829$ There is strong evidence that severely emphysematous lungs have increased numbers of apoptotic cells. ${ }^{26}$ The first study to mechanistically implicate apoptosis in the development of emphysema demonstrated that inhibition of the angiogenic and pro-endothelial cell survival vascular endothelial growth factor (VEGF) causes pulmonary endothelial cell apoptosis. ${ }^{28}{ }^{30}$ The relevance of the VEGFR blockade model to human emphysema is that both have decreased VEGF signalling, decreased number of lung capillaries and increased oxidative stress and alveolar cell apoptosis. In the VEGF blockade model however, the apoptosis dependent alveolar destruction proceeds without inflammation, ${ }^{28}{ }^{31}$ thus showing for the first time that apoptosis plays a distinct pathogenic role in alveolar destruction and emphysema development. Apoptosis has been classically described as a process of coordinated removal of unwanted cells without stimulating inflammation. Furthermore, physiological apoptosis would lead to a local anti-inflammatory environment characterised by production of prostaglandin E2 and transforming growth factor $\beta .^{32}$ In the context of emphysema, Henson proposed that excessive alveolar cell apoptosis or impaired apoptotic cell clearance would cause inflammation from prolonged exposure of nuclear and cytoplasmic contents of dying cells. ${ }^{33}$ In an editorial written in 2003, we framed apoptosis as the missing link in the pathogenesis of emphysema. ${ }^{34}$ Since then, additional evidence supported the notion that abnormal levels of apoptosis may invoke an inflammatory response. For example, Zheng et al linked apoptosis to excessive inflammation caused by upregulation of interferon $\gamma^{35}$ The most striking result of their studies was that blockade of apoptosis significantly reduced inflammation, ${ }^{35}$ thus positioning, for the first time, apoptosis upstream of alveolar inflammation and emphysema. Another potential link between inflammatory and apoptotic pathways has been shown with work on alpha 1 antitrypsin, a well known protective factor against emphysema. Alpha 1 antitrypsin is a serum bona fide anti-inflammatory protease inhibitor, but which we found to also enter lung endothelial cells, ${ }^{36}$ where it plays an antiapoptotic role against injurious stimuli both in cell culture ${ }^{36}$ and in vivo. ${ }^{37}$ Finally, abundant data implicate injurious levels of oxidative stress, usually attributed to cigarette smoke or phagocyte activation, in the pathogenesis of emphysema. ${ }^{38}{ }^{39}$ Erythrocytes and alveolar macrophages from smokers show altered activities of antioxidant enzymes such as superoxide dismutase, catalase and glutathione peroxidase, which are hypothesised to be initially activated, but eventually downregulated, therefore overwhelming their ability to scavenge the excess free radicals. ${ }^{39}{ }^{40}$ It is by now well recognised that reactive oxygen species play various roles in the cellular biological responses, from physiological intracellular signalling, to injury and cell death.

Like most studies attempting to elucidate the pathogenesis of emphysema, a complex disease which takes decades to manifest clinically, the investigations into the mechanisms of HIV related emphysema are primarily using observational studies in humans, translational studies utilising human derived specimens, basic studies of the virus in cell culture systems and animal models of disease. As most laboratory animal species are not susceptible to HIV infections, it is even more difficult to develop complex models of HIV related lung pathology, having 
Figure 2 (A) Lymphocytic alveolitis, defined as greater than 15\% lymphocytes in bronchoalveolar lavage (BAL) (broken line), is common and may persist in HIV infected subjects in the absence of highly active antiretroviral therapy treatment (HAART) (reprinted with permission from Twigg and colleagues ${ }^{47}$ ). Bars represent individual HIV patients studied in the preHAART era (black bars $=$ first bronchoscopy, white bars = second bronchoscopy 11 (9.7) months later). $(B, C)$ Typical appearance of BAL showing lymphocytic inflammation in an asymptomatic HIV positive patient (B). Microphotograph $(10 \times$ magnification) of Wright-Giemsa stained BAL showing alveolar macrophages (arrowhead) and a large number of lymphocytes (arrows). (C) Microphotograph $(20 \times$ magnification) of BAL stained by immunocytochemistry with a CD8 specific antibody showing increased presence of CD8 positive T lymphocytes (brown, arrow) in the BAL from the same HIV positive patient.
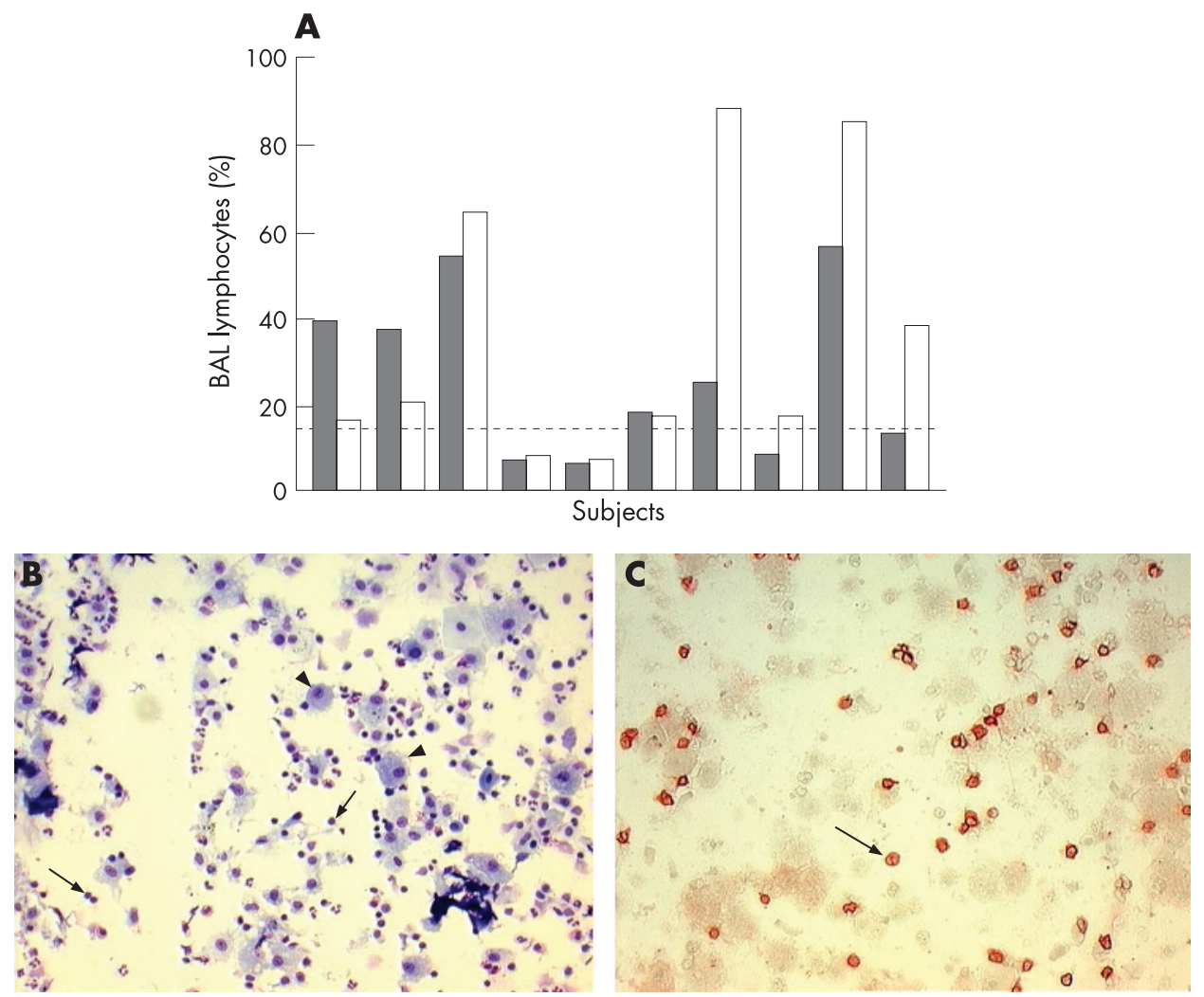

to rely on expensive non-human primate models of HIV infection using the simian immunodeficiency virus. Next, we will summarise data available from all these levels of investigation that may suggest pathogenic mechanisms of HIV induced lung alveolar destruction, with the understanding that most of the in vitro or data derived from other organs affected with HIV will have to await confirmation in lung models of disease in vivo and even in human studies before being widely adopted.

\section{HIV and lung inflammation}

The extent of inflammatory reaction in emphysema is variable. The role of inflammation in the development of emphysema has been traditionally supported by the protease/antiprotease imbalance theory. Patients with low levels of alpha 1 antitrypsin are highly susceptible to smoking induced emphysema. Furthermore, instillation of elastase is a classical experimental model of emphysema. The sources of excessive proteases are postulated to be the polymorphonuclear cells that release neutrophil elastase and proteinase 3 and the macrophages, which release matrix metalloproteases. However, in the 1990s, studies reported accumulation of CD8+ T cells in the lungs of patients with severe COPD. ${ }^{41-43}$ Subsequent work demonstrated that these cells express a T helper type 1 (Th1) cytokine profile, ${ }^{8}$ a pattern suggestive of a cytotoxic $\mathrm{T}$ lymphocyte phenotype (CTL). ${ }^{44}$ The potential role of CTL in the pathogenesis of emphysema is further supported by animal models demonstrating that pulmonary viral infections, which typically lead to a localised CTL immune response, are important cofactors in the development of disease. ${ }^{45}$ Given these observations, it is not surprising that emphysema is found in HIV infected subjects, whose lung response to the HIV infection is characterised by the accumulation of CD8+ cells in the alveolar space (fig 2). ${ }^{46}{ }^{47} \mathrm{In}$ fact, lymphocytic alveolitis, defined as greater than $15 \%$ lymphocytes in bronchoalveolar lavage, is a common finding in HIV infected subjects (fig 2A, 2B). These lymphocytes typically express CD8 (fig 2C), consistent with their CTL phenotype. ${ }^{46}$

How might the presence of CTL in the lung lead to emphysema in HIV infected subjects? There are several potential mechanisms. We and others have shown that the production of interferon $\gamma$ is increased in the lungs of HIV infected subjects, ${ }^{48}{ }^{49}$ likely coming primarily from CD8+ CTL. This could lead to a state of chronic alveolar macrophage activation and chronic inflammation in the lung. Second, when CTL encounter their antigenic targets they release perforins and proteases which could directly damage the lung. ${ }^{50}$ Third, perforins and proteases have also been shown to induce apoptosis in lung cells, ${ }^{51}$ further leading to lung destruction. Thus CD8+ cells can influence lung parenchymal destruction through many different mechanisms.

If CD8+ CTLs are important in the pathogenesis of emphysema, what is the "antigen" that drives this response in HIV infected subjects? Clearly, common respiratory viruses could contribute in much the same way they are postulated to do so in non-HIV infected subjects with emphysema. Pneumocystis has also been shown to evoke a CTL response ${ }^{52}$ and the emphysema seen in HIV infected subjects frequently occurs in the apex, a site where Pneumocystis is commonly present. Other pathogens commonly found in HIV infection can also induce a CTL response, including tuberculosis. ${ }^{53}$ The HIV particles or HIV derived molecules may contain the "antigen" as well. For example, Tat (transactivator of transcription protein) is a transactivator of the HIV-1 long terminal repeat, required for viral gene expression and replication which can be secreted. Another potentially important chemokine secreted in response to HIV infection, and in particular to the HIV 1-Nef protein ${ }^{54}$ is interferon inducible protein 10 (IP-10), which may contribute to CTL chemoattraction. ${ }^{55}$ Nef is an 
$N$-myristoylated adaptor protein which interacts with multiple cellular signalling pathways and immune cell receptors ${ }^{56-59}$ contributing to the maintenance of high viral loads during HIV infection and possibly the HIV associated pulmonary vasculopathy. ${ }^{60}$ While Tat stimulates monocytes via activation of VEGF receptor $1^{61}$ and Nef may act via CXCR3 receptor, ${ }^{55}$ an intriguing possibility is that HIV itself perpetuates the CTL response. ${ }^{46}$ In this regard, we have shown in cross sectional studies that the presence of lymphocytic alveolitis correlates with the ability to detect HIV in bronchoalveolar lavage fluid. ${ }^{47}$ Moreover, HIV RNA was detected primarily in cells adjacent to emphysematous areas of the lung rather than in normal appearing lungs of AIDS associated emphysema lungs examined at autopsy. ${ }^{62}$

Furthermore, in a recently completed longitudinal study, we demonstrated that HAART was associated with a significant decrease in the number of CD8+ cells in the alveolar space (manuscript submitted). This raises the interesting possibility that the incidence of COPD in HIV infected subjects may decrease significantly in the HAART era, a question not yet answered by clinical trials to date. Finally, autoantigens generated during chronic inflammation may lead to development of autoreactive CTL. Thus there is no shortage of potential antigenic stimuli to drive a CD8+ cytotoxic $\mathrm{T}$ cell response in HIV infected subjects.

In addition, HIV seems to infect the alveolar macrophages in the lungs of HIV seropositive individuals. This in turn has been postulated to lead to overexpression of matrix metalloproteinases in adjacent cells which may lead to destruction of the basement membranes and the development of emphysema. ${ }^{17}$

\section{HIV and endothelial cell dysfunction and apoptosis}

The known effects of HIV infection on endothelial cell function appear to be linked to angiogenesis (both increased, abnormal angiogenesis and inhibition of angiogenesis with endothelial cell death) and the signalling of the proangiogenic VEGF. One of the first recognised tumours associated with the HIV infection was the Kaposi sarcoma, a highly vascular tumour characterised by neoplastic growth of blood vessels, subsequently attributed to

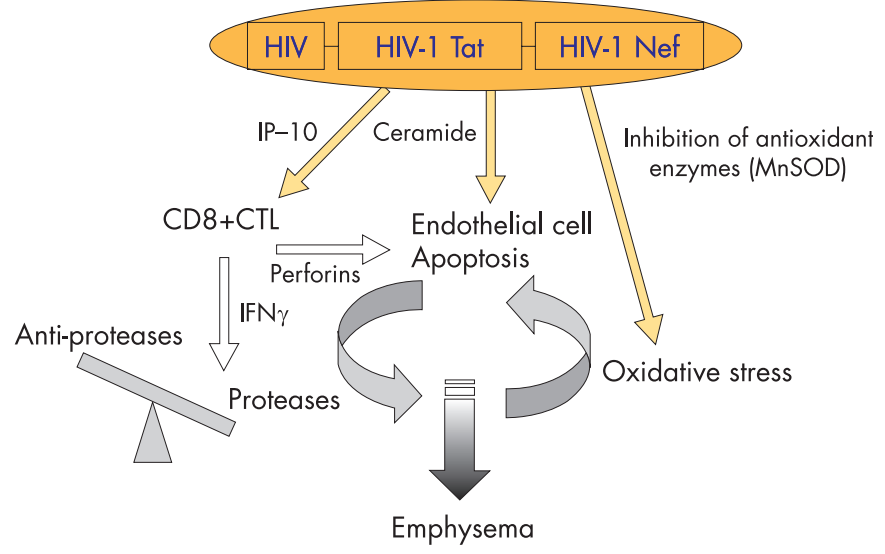

Figure 3 Schematic diagram with the putative mechanisms involved in the HIV associated pulmonary emphysema development. HIV or the HIVTat protein engaging mechanisms important in the development of lung emphysema, such as an imbalance of protease/antiproteases, oxidative stress and alveolar endothelial cell apoptosis. CTL, cytotoxic $T$ lymphocyte; IFN $\gamma$, interferon $\gamma$; IP-10, interferon inducible protein 10; Tat, transactivator of transcription protein. human herpes virus 8 infection (HHV-8). Although VEGF serum levels do not appear to correlate with HIV or HHV infection, ${ }^{63} \mathrm{HHV}-8$ infection stimulates endothelial cell transformation via enhanced VEGF and VEGF R expression, leading to Kaposi sarcoma. ${ }^{64}$ The extracellularly secreted Tat has been primarily involved in the regulation of angiogenesis, although there are reports of a direct proapoptotic effect on lung microvascular endothelial cells in vitro. ${ }^{65}$ Compared with VEGF, extracellular Tat exerts distinct effects on endothelial cells, for example stimulation of MAPK ERK is not required for its angiogenic response, ${ }^{66}$ but like other growth factors it binds heparin. ${ }^{67}$ Interestingly, Tat itself binds VEGF receptor 2 (KDR). The proposed binding site is its basic domain ${ }^{67}$ which exhibited a low specificity and high affinity for binding KDR. ${ }^{68}$ However, other domains of Tat may bind VEGF receptors. ${ }^{69}$ Twenty amino acid and 12 amino acid peptides corresponding to the cysteine rich and basic domains, respectively, of HIV-1 Tat also inhibited VEGF binding to KDR and neuropilin 1 receptors in endothelial cells. These Tat peptides inhibited VEGF induced ERK activation and mitogenesis in endothelial cells, and inhibited angiogenesis in vitro at concentrations similar to those which inhibited VEGF receptor binding. These peptides also inhibited proliferation, angiogenesis and ERK activation induced by basic fibroblast growth factor (bFGF) with similar potency and efficacy. Surprisingly, we found that both cysteine rich and basic domain Tat peptides strikingly induced apoptosis in endothelial cells, independent of their effects on VEGF and bFGF. Furthermore, we found no evidence for direct biological effects of recombinant Tat on VEGF receptor binding, ERK activation, endothelial cell survival or mitogenesis. ${ }^{70}$ In summary, cell culture studies suggested that individual peptides from both basic and cysteine rich domains induced apoptosis of endothelial cells independent of VEGF interaction and inhibited angiogenesis. ${ }^{70}$ The cysteine rich peptides were more potent than the basic at inducing endothelial cell apoptosis. ${ }^{70}$ The proangiogenic effects of Tat are likely indirect through the release of bFGF and ligation of integrins $\alpha_{5} \beta_{1}$ and $\alpha_{v} \beta_{3} .{ }^{70}$ These effects in the lung may oppose the effect of VEGF and cause excessive lung microvascular endothelial cell apoptosis. ${ }^{71}$ Microvascular endothelial cell apoptosis may be also triggered by HIV-1 Nef which has been shown to trigger brain microvascular endothelial cell apoptosis. ${ }^{72}$ However, the net effect of Nef on the lung endothelial cell may be dependent on cooperative activity of immune cells. In this regard, prompt clearance of apoptotic endothelial cells and selection for apoptosis resistant endothelium may trigger aberrant angiogenesis in the lung. ${ }^{60}$

Can HIV cause apoptosis of lung cells directly? HIV accelerates FAS and ceramide induced apoptosis of Jurkat cells in culture via the gp160 dependent calmodulin upregulation. ${ }^{73} 74$ HIV1 causes neuronal apoptosis via monocyte derived tumour necrosis factor $\alpha$ (and ceramide) and platelet activator factor receptor activation. ${ }^{75}$ Interestingly, ceramide has been shown to enhance HIV viral transcription and HIV production in myelomonocytic cells latently infected with $\mathrm{HIV}^{76}$ and is sustained by autocrine tumour necrosis factor synthesis. ${ }^{77} \mathrm{~A}$ metabolic product of ceramide, galactosylceramide, serves as a portal of cellular entry for HIV-1 virion via gp120 binding to this lipid receptor. ${ }^{78} 79$ In neuronal cells, both Tat and gp 120 induced ceramide production as well as oxidative stress. ${ }^{80}$ It is conceivable therefore that HIV and ceramide reciprocally augment their production, with deleterious effects for lung homeostasis. In this context, we have shown increased ceramide levels in the lungs of patients with emphysema and a 
pathogenic role for ceramide overproduction in the development of murine emphysema. ${ }^{3136}$

\section{HIV and oxidative stress}

Interestingly, it has been noted that while systemic levels of glutathione are lower in HIV+ individuals, ${ }^{81}$ there are higher reduced glutathione levels in the upper lobes of HIV seropositive patients compared with the middle lobe independent of smoking status. ${ }^{82}$ It is unclear the reasons behind these localised increases at a site with a more pronounced lung damage (upper lobes), where oxidative stress is expected to be higher and therefore to consume the reduced glutathione. Evidence for a repressed antioxidant system in HIV comes also from our studies in cell cultures, where Tat directly interacted and repressed the expression of manganese superoxide dismutase ${ }^{83}$ and seleno-glutathione peroxidase, ${ }^{84}$ potent antioxidant enzymes. Thus the alterations in redox homeostasis in the lung may predispose to accumulation of reactive oxygen species and increased susceptibility to emphysema.

\section{Other potential mechanisms of HIV associated emphysema}

Malnutrition may play a role in the development of emphysema ${ }^{85}$ in HIV infected patients. Indeed, the body mass index was the most important clinical variable associated with decreased carbon monoxide diffusion capacities among the HIV+ subjects. ${ }^{7}$ How starvation causes emphysema is not yet known, and may involve increased apoptosis and cytotoxic lymphocyte activation. ${ }^{86}$ Similarly, whether any relationship exists between HIV infection and acceleration of senescence which has been recently implicated in the emphysema phenotype is currently unknown. ${ }^{87} 88$ Traditionally, HIV infection has been associated with increased replicative senescence of immune cells, ${ }^{89}$ but how these findings relate to an exuberant cytotoxic lymphocytic response in the lung or to an increased senescent profile of parenchymal lung cells ${ }^{90}$ remains to be elucidated.

In conclusion, HIV seropositive individuals have a propensity to develop emphysematous changes in their upper lobes at an accelerated rate independent of smoking status. Confounding factors in HIV infected individuals, including Pneumocystis colonisation, drug use and malnutrition may play a role in the predisposition for emphysema. However, HIV itself is emerging as an independent factor in the pathogenesis of emphysema (schematic diagram summarising the putative mechanisms is shown in fig 3). It remains to be determined whether HAART therapy can prevent or retard the development of HIV related emphysema. Understanding the processes that trigger emphysema in HIV infected individuals may unravel the mechanisms of cigarette smoke related emphysema in non-infected patients as well.

Acknowledgements: The authors wish to thank Ms Patricia Smith for providing the normal BAL microphotograph and Shawn D Teague, MD, for contributing with the CT scan images.

Competing interests: None.

\section{REFERENCES}

1. Jaffe HW, Bregman DJ, Selik RM. Acquired immune deficiency syndrome in the United States: the first 1,000 cases. J Infect Dis 1983;148:339-45.

2. Kuhlman JE, Knowles MC, Fishman EK, et al. Premature bullous pulmonary damage in AIDS: CT diagnosis. Radiology 1989;173:23-6.

3. The definition of emphysema. Report of a National Heart, Lung, and Blood Institute, Division of Lung Diseases workshop. Am Rev Respir Dis 1985;132:182-5.

4. Diaz PT, Wewers MD, Pacht E, et al. Respiratory symptoms among HIV-seropositive individuals. Chest 2003:123:1977-82.
5. Diaz PT, Clanton TL, Pacht ER. Emphysema-like pulmonary disease associated with human immunodeficiency virus infection. Ann Intern Med 1992;116:124-8.

6. Crothers K, Butt AA, Gibert CL, et al. Increased COPD among HIV-positive compared to HIV-negative veterans. Chest 2006;130:1326-33.

7. Diaz PT, King MA, Pacht ER, et al. Increased susceptibility to pulmonary emphysema among HIV-seropositive smokers. Ann Intern Med 2000;132:369-72.

8. Grumelli S, Corry DB, Song LZ, et al. An immune basis for lung parenchymal destruction in chronic obstructive pulmonary disease and emphysema. PLoS Med 2004:1:e8.

9. Morris A, Kingsley LA, Groner G, et al. Prevalence and clinical predictors of Pneumocystis colonization among HIV-infected men. Aids 2004;18:793-8.

10. Huang L, Crothers K, Morris A, et al. Pneumocystis colonization in HIV-infected patients. J Eukaryot Microbiol 2003;50(Suppl):616-17.

11. Morris A, Sciurba FC, Lebedeva IP, et al. Association of chronic obstructive pulmonary disease severity and Pneumocystis colonization. Am J Respir Crit Care Med 2004;170:408-13.

12. Norris KA, Morris A, Patil S, et al. Pneumocystis colonization, airway inflammation, and pulmonary function decline in acquired immunodeficiency syndrome. Immunol Res 2006:36:175-87.

13. Gurney JW, Bates FT. Pulmonary cystic disease: comparison of Pneumocystis carinii pneumatoceles and bullous emphysema due to intravenous drug abuse. Radiology 1989:173:27-31.

14. Goldstein DS, Karpel JP, Appel D, et al. Bullous pulmonary damage in users of intravenous drugs. Chest 1986;89:266-9.

15. Schmidt RA, Glenny RW, Godwin JD, et al. Panlobular emphysema in young intravenous Ritalin abusers. Am Rev Respir Dis 1991;143:649-56.

16. Stern EJ, Frank MS, Schmutz JF, et al. Panlobular pulmonary emphysema caused by i.v. injection of methylphenidate (Ritalin): findings on chest radiographs and CT scans. AJR Am J Roentgenol 1994;162:555-60.

17. Pare JP, Cote G, Fraser RS. Long-term follow-up of drug abusers with intravenous talcosis. Am Rev Respir Dis 1989;139:233-41.

18. Ward S, Heyneman LE, Reittner $P$, et al. Talcosis associated with IV abuse of oral medications: CT findings. AJR Am J Roentgenol 2000;174:789-93.

19. Johnson MK, Smith RP, Morrison D, et al. Large lung bullae in marijuana smokers. Thorax 2000;55:340-2.

20. Tuder RM, Yoshida T, Arap W, et al. State of the art. Cellular and molecular mechanisms of alveolar destruction in emphysema: an evolutionary perspective. Proc Am Thorac Soc 2006;3:503-10.

21. Senior RM, Tegner $\mathrm{H}$, Kuhn $\mathrm{C}$, et al. The induction of pulmonary emphysema with human leukocyte elastase. Am Rev Respir Dis 1977;116:469-75.

22. Morris DG, Huang $X$, Kaminski N, et al. Loss of integrin alpha(v)beta6-mediated TGFbeta activation causes Mmp12-dependent emphysema. Nature 2003;422:169-73.

23. MacNee W, Wiggs B, Belzberg AS, et al. The effect of cigarette smoking on neutrophil kinetics in human lungs. N Engl J Med 1989;321:924-8.

24. Hogg JC, Chu F, Utokaparch S, et al. The nature of small-airway obstruction in chronic obstructive pulmonary disease. N Engl J Med 2004;350:2645-53.

25. Ofulue AF, Ko M. Effects of depletion of neutrophils or macrophages on development of cigarette smoke-induced emphysema. Am J Physiol 1999;277(1 Pt 1):L97-105.

26. Kasahara Y, Tuder RM, Cool CD, et al. Endothelial cell death and decreased expression of vascular endothelial growth factor and vascular endothelial growth factor receptor 2 in emphysema. Am J Respir Crit Care Med 2001;163(3 Pt 1):73744.

27. Aoshiba K, Yokohori N, Nagai A. Alveolar wall apoptosis causes lung destruction and emphysematous changes. Am J Respir Cell Mol Biol 2003;28:555-62.

28. Kasahara Y, Tuder RM, Taraseviciene-Stewart L, et al. Inhibition of VEGF receptors causes lung cell apoptosis and emphysema. J Clin Invest 2000;106:1311-19.

29. Tuder RM, Zhen L, Cho CY, et al. Oxidative stress and apoptosis interact and cause emphysema due to vascular endothelial growth factor receptor blockade. Am J Respir Cell Mol Biol 2003;29:88-97

30. Tang K, Rossiter HB, Wagner PD, et al. Lung-targeted VEGF inactivation leads to an emphysema phenotype in mice. J Appl Physiol 2004;97:1559-66.

31. Petrache I, Natarajan V, Zhen L, et al. Ceramide upregulation causes pulmonary cell apoptosis and emphysema-like disease in mice. Nat Med 2005;11:491-8.

32. Rose DM, Fadok VA, Riches DW, et al. Autocrine/paracrine involvement of plateletactivating factor and transforming growth factor-beta in the induction of phosphatidylserine recognition by murine macrophages. J Immunol 1995;155:581925.

33. Henson PM. Possible roles for apoptosis and apoptotic cell recognition in inflammation and fibrosis. Am J Respir Cell Mol Biol 2003;29(Suppl):S70-6.

34. Tuder RM, Petrache I, Elias JA, et al. Apoptosis and emphysema: the missing link. Am J Respir Cell Mol Biol 2003;28:551-4.

35. Zheng T, Kang MJ, Crothers K, et al. Role of cathepsin S-dependent epithelial cell apoptosis in IFN-\{gamma $\}$-induced alveolar remodeling and pulmonary emphysema. $\mathrm{J}$ Immunol 2005;174:8106-15.

36. Petrache I, Fijalkowska I, Medler TR, et al. \{alpha\}-1 Antitrypsin inhibits caspase-3 activity, preventing lung endothelial cell apoptosis. Am J Pathol 2006;169:1155-66.

37. Petrache I, Fijalkowska I, Zhen L, et al. A novel anti-apoptotic role for alpha-1 antitrypsin in the prevention of pulmonary emphysema. Am J Respir Crit Care Med 2006;173:1222-8.

38. Cantin A, Crystal RG. Oxidants, antioxidants and the pathogenesis of emphysema Eur J Respir Dis Supp/ 1985;139:7-17. 
39. McCusker K, Hoidal J. Selective increase of antioxidant enzyme activity in the alveolar macrophages from cigarette smokers and smoke-exposed hamsters. Am Rev Respir Dis 1990;141:678-82.

40. Yildiz L, Kayaoglu N, Aksoy $\mathrm{H}$. The changes of superoxide dismutase, catalase and glutathione peroxidase activities in erythrocytes of active and passive smokers. Clin Chem Lab Med 2002;40:612-15.

41. Retamales I, Elliott WM, Meshi B, et al. Amplification of inflammation in emphysema and its association with latent adenoviral infection. Am J Respir Crit Care Med 2001:164:469-73.

42. Saetta M, Baraldo S, Corbino L, et al. CD8+ve cells in the lungs of smokers with chronic obstructive pulmonary disease. Am J Respir Crit Care Med 1999;160:71117.

43. Di Stefano A, Caramori G, Ricciardolo FL, et al. Cellular and molecular mechanisms in chronic obstructive pulmonary disease: an overview. Clin Exp Allergy 2004:34:1156-67.

44. Fong TA, Mosmann TR. Alloreactive murine CD8+ T cell clones secrete the Th pattern of cytokines. J Immunol 1990;144:1744-52.

45. Meshi B, Vitalis TZ, Ionescu D, et al. Emphysematous lung destruction by cigarette smoke. The effects of latent adenoviral infection on the lung inflammatory response. Am J Respir Cell Mol Biol 2002;26:52-7.

46. Plata $\mathbf{F}$, Autran B, Martins LP, et al. AIDS virus-specific cytotoxic T lymphocytes in lung disorders. Nature 1987;328:348-51.

47. Twigg HL, Soliman DM, Day RB, et al. Lymphocytic alveolitis, bronchoalveolar lavage viral load, and outcome in human immunodeficiency virus infection. Am J Respir Crit Care Med 1999;159(5 Pt 1):1439-44

48. Twigg HL 3rd, Spain BA, Soliman DM, et al. Production of interferon-gamma by lung lymphocytes in HIV-infected individuals. Am J Physiol 1999;276(2 Pt 1):L256-62.

49. Buhl R, Jaffe HA, Holroyd KJ, et al. Activation of alveolar macrophages in asymptomatic HIV-infected individuals. J Immunol 1993;150:1019-28.

50. Chrysofakis G, Tzanakis N, Kyriakoy D, et al. Perforin expression and cytotoxic activity of sputum CD8+ lymphocytes in patients with COPD. Chest 2004:125:71-6.

51. Agostini C, Siviero M, Facco M, et al. Antiapoptotic effects of IL-15 on pulmonary Tc1 cells of patients with human immunodeficiency virus infection. Am J Respir Crit Care Med 2001:163:484-9.

52. Meissner NN, Lund FE, Han S, et al. CD8 T cell-mediated lung damage in response to the extracellular pathogen pneumocystis is dependent on $\mathrm{MHC}$ class I expression by radiation-resistant lung cells. J Immunol 2005:175:8271-9.

53. Lewinsohn DA, Heinzel AS, Gardner JM, et al. Mycobacterium tuberculosis-specific CD8+ T cells preferentially recognize heavily infected cells. Am J Respir Crit Care Med 2003:168:1346-52.

54. van Marle G, Henry S, Todoruk T, et al. Human immunodeficiency virus type 1 Nef protein mediates neural cell death: a neurotoxic role for IP-10. Virology 2004;329:302-18.

55. Agostini C, Facco M, Siviero M, et al. CXC chemokines IP-10 and mig expression and direct migration of pulmonary CD8+/CXCR3 $+T$ cells in the lungs of patients with HIV infection and T-cell alveolitis. Am J Respir Crit Care Med 2000;162(4 Pt 1):146673.

56. Schwartz 0, Marechal V, Le Gall S, et al. Endocytosis of major histocompatibility complex class I molecules is induced by the HIV-1 Nef protein. Nat Med 1996;2:33842.

57. Geleziunas R, Xu W, Takeda K, et al. HIV-1 Nef inhibits ASK1-dependent death signalling providing a potential mechanism for protecting the infected host cell. Nature 2001:410:834-8.

58. Stoddart CA, Geleziunas R, Ferrell $\mathrm{S}$, et al. Human immunodeficiency virus type 1 Nef-mediated downregulation of CD4 correlates with Nef enhancement of viral pathogenesis. J Virol 2003;77:2124-33.

59. Cho S, Knox KS, Kohli LM, et al. Impaired cell surface expression of human CD1d by the formation of an HIV-1 Nef/CD1d complex. Virology 2005;337:242-52.

60. Marecki JC, Cool CD, Parr JE, et al. HIV-1 Nef is associated with complex pulmonary vascular lesions in SHIV-nef-infected macaques. Am J Respir Crit Care Med 2006:174:437-45.

61. Mitola S, Sozzani S, Luini W, et al. Tat-human immunodeficiency virus-1 induces human monocyte chemotaxis by activation of vascular endothelial growth factor receptor-1. Blood 1997;90:1365-72.

62. Yearsley MM, Diaz PT, Knoell D, et al. Correlation of HIV-1 detection and histology in AIDS-associated emphysema. Diagn Mol Pathol 2005;14:48-52.

63. Renwick N, Weverling GJ, Brouwer J, et al. Vascular endothelial growth facto levels in serum do not increase following HIV type 1 and HHV8 seroconversion and lack correlation with AIDS-related Kaposi's sarcoma. AIDS Res Hum Retroviruses 2002;18:695-8.
64. Masood R, Cesarman E, Smith DL, et al. Human herpesvirus-8-transformed endothelial cells have functionally activated vascular endothelial growth factor/ vascular endothelial growth factor receptor. Am J Pathol 2002;160:23-9.

65. Park IW, Ullrich CK, Schoenberger E, et al. HIV-1 Tat induces microvascular endothelial apoptosis through caspase activation. J Immunol 2001;167:2766-71.

66. Rusnati M, Urbinati C, Musulin B, et al. Activation of endothelial cell mitogen activated protein kinase ERK(1/2) by extracellular HIV-1 Tat protein. Endothelium 2001;8:65-74.

67. Albini A, Benelli R, Presta $\mathrm{M}$, et al. HIV-tat protein is a heparin-binding angiogenic growth factor. Oncogene 1996;12:289-97.

68. Demirovic AR, Canadi J, Weiglhofer W, et al. HIV TAT basic peptide is not a highaffinity ligand for VEGF receptor 2. Biol Chem 2003;384:1435-41.

69. Scheidegger $\mathbf{P}$, Weiglhofer W, Suarez $\mathbf{S}$, et al. Signalling properties of an HIVencoded angiogenic peptide mimicking vascular endothelial growth factor activity. Biochem J 2001;353(Pt 3):569-78.

70. Jia H, Lohr M, Jezequel S, et al. Cysteine-rich and basic domain HIV-1 Tat peptides inhibit angiogenesis and induce endothelial cell apoptosis. Biochem Biophys Res Commun 2001;283:469-79.

71. Tuder RM, McGrath S, Neptune E. The pathobiological mechanisms of emphysema models: what do they have in common? Pulm Pharmacol Ther 2003;16:67-78.

72. Acheampong EA, Parveen Z, Muthoga LW, et al. Human immunodeficiency virus type 1 Nef potently induces apoptosis in primary human brain microvascular endothelial cells via the activation of caspases. J Virol 2005;79:4257-69.

73. Micoli KJ, Mamaeva 0, Piller SC, et al. Point mutations in the C-terminus of HIVgp160 reduce apoptosis and calmodulin binding without affecting viral replication. Virology 2006;344:468-79.

74. Micoli KJ, Pan G, Wu Y, et al. Requirement of calmodulin binding by HIV-1 gp160 for enhanced FAS-mediated apoptosis. J Biol Chem 2000;275:1233-40.

75. Perry SW, Hamilton JA, Tjoelker LW, et al. Platelet-activating factor receptor activation. An initiator step in HIV-1 neuropathogenesis. J Biol Chem 1998:273:17660-4

76. Papp B, Zhang D, Groopman JE, et al. Stimulation of human immunodeficiency virus type 1 expression by ceramide. AIDS Res Hum Retroviruses 1994;10:775-80.

77. Rivas $\mathbf{C l}$, Golde DW, Vera JC, et al. Involvement of the sphingomyelin pathway in autocrine tumor necrosis factor signaling for human immunodeficiency virus production in chronically infected HL-60 cells. Blood 1994;83:2191-7.

78. Harouse JM, Bhat S, Spitalnik SL, et al. Inhibition of entry of HIV-1 in neural cell lines by antibodies against galactosyl ceramide. Science 1991;253:320-3.

79. Bhat S, Spitalnik SL, Gonzalez-Scarano F, et al. Galactosyl ceramide or a derivative is an essential component of the neural receptor for human immunodeficiency virus type 1 envelope glycoprotein gp120. Proc Natl Acad Sci U S A 1991;88:7131-4.

80. Haughey NJ, Cutler RG, Tamara A, et al. Perturbation of sphingolipid metabolism and ceramide production in HIV-dementia. Ann Neurol 2004:55:257-67.

81. Buhl R, Jaffe HA, Holroyd KJ, et al. Systemic glutathione deficiency in symptom-free HIV-seropositive individuals. Lancet 1989;2:1294-8.

82. Diaz PT, Wewers MD, King $\mathrm{M}$, et al. Regional differences in emphysema scores and BAL glutathione levels in HIV-infected individuals. Chest 2004;126:1439-42.

83. Flores SC, Marecki JC, Harper KP, et al. Tat protein of human immunodeficiency virus type 1 represses expression of manganese superoxide dismutase in HeLa cells. Proc Natl Acad Sci U S A 1993:90:7632-6.

84. Richard MJ, Guiraud P, Didier C, et al. Human immunodeficiency virus type 1 Tat protein impairs selenoglutathione peroxidase expression and activity by a mechanism independent of cellular selenium uptake: consequences on cellular resistance to UV-A radiation. Arch Biochem Biophys 2001;386:213-20.

85. Sahebjami H, Wirman JA. Emphysema-like changes in the lungs of starved rats. Am Rev Respir Dis 1981;124:619-24.

86. Massaro D, Massaro GD. Hunger disease and pulmonary alveoli. Am J Respir Crit Care Med 2004:170:723-4.

87. Kasagi S, Seyama K, Mori H, et al. Tomato juice prevents senescence-accelerated mouse P1 strain from developing emphysema induced by chronic exposure to tobacco smoke. Am J Physiol Lung Cell Mol Physiol 2006;290:L396-404.

88. Tuder RM. Aging and cigarette smoke: fueling the fire. Am J Respir Crit Care Med 2006;174:490-1.

89. van Baarle D, Tsegaye A, Miedema F, et al. Significance of senescence for virus specific memory $T$ cell responses: rapid ageing during chronic stimulation of the immune system. Immunol Lett 2005;97:19-29.

90. Tsuji T, Aoshiba K, Nagai A. Alveolar cell senescence in patients with pulmonary emphysema. Am J Respir Crit Care Med 2006:174:886-93. 